\title{
Rainfall probability analysis for crop planning in Deogarh district of Odisha, India
}

\author{
C.R.Subudhi* , Sukanya Suryavanshi, Nibedita Jena and R.Subudhi \\ Department of Soil and Water Cons. and Eng, CAET, OUAT, Bhubaneswar-751003, Odisha \\ *Email: rsubudhi5906@gmail.com, +919437645234
}

\begin{abstract}
This study was under taken in the U.G. thesis work in the Dept. Of SWCE, CAET, OUAT, Bhubaneswar during the year 2018-19. Deogarh district has geographical area of 2781.66 sq.km. and latitude of $21^{\circ} 35^{\prime} \mathrm{N}$ and a longitude of $84^{\circ} 30^{\prime} \mathrm{E}$. The average rainfall at Deogarh district is around $1514.8 \mathrm{~mm}$, though it receives high amount rainfall but most of the rainfall occurred during kharif. So most of the crops get low yield due to improper crop planning. Thus, this study is proposed to be undertaken with the following objective: Probability analysis of annual, seasonal and monthly rainfall data of Deogarh district. So rainfall data were collected from OUAT, Agril Meteorology Dept. from 2001 to 2017(17 years) monthly, seasonal and annual rainfall were analyzed .Probability analysis have been made and equations were fitted to different distributions and best fitted equations were tested. Monthly, Annual and seasonal probability analysis of rainfall data shows the probability rainfall distribution of Deogarh district in different months, years and seasons. It is observed that rainfall during June to Sep is slightly less than $1000 \mathrm{~mm}$ and cropping pattern like paddy(110 days) may be followed by mustard is suitable to this region. Also if the kharif rain can be harvested and it can be reused for another rabi crop by using sprinkler or drip irrigation, which will give benefit to the farmers. Annual rainfall of Deogarh district is $1514.8 \mathrm{~mm}$ at $50 \%$ probability level.
\end{abstract}

Key words: Crop planning, probability analysis, rainfall

Paper cited: Subudhi, C. R.; Suryavanshi, S.; Jena, N. and Subudhi, R. (2019). Rainfall probability analysis for crop planning in Deogarh district of Odisha, India. South Asian Journal of Food Technology and Environment, 5(2): 840-845.

\section{Introduction}

Deogarh district has geographical area of 2781.66 sq.km. and latitude of $21^{\circ} 35^{\prime} \mathrm{N}$ and a longitude of $84^{\circ} 30^{\prime} \mathrm{E}$. The average rainfall at Deogarh district is $1514.8 \mathrm{~mm}$, most of the rainfall occurred during kharif. Thus, this study is proposed to be undertaken with the following objective: Probability analysis of annual, seasonal and monthly rainfall data of Deogarh district. Thom (1966) employed mixed gamma probability distribution for describing skewed rainfall data and employed approximate solution to non-linear equations obtained by differentiating log likelihood function with respect to the parameters of the distribution. Subsequently, this methodology along with variance ratio test as a goodnessof-fit has been widely employed Kar et al., (2004), Jat et al., (2006), Senapati et al.,
(2009) applied incomplete gamma probability distribution for rainfall analysis. In addition to gamma probability distribution, other twoparameter probability distributions (normal, log-normal, Weibull, smallest and largest extreme value), and three-parameter probability distributions (log-normal, gamma, log-logistic and Weibull) have been widely used for studying flood frequency, drought analysis and rainfall probability analysis (Senapati et al., 2009). Gumbel (1954) and Chow (1964) have applied gamma distribution with two and three parameter, Pearson typeIII, extreme value, binomial and Poisson distribution to hydrological data (Weibull, 1951). 


\section{Materials and methods}

The data were collected from District Collector's Office, Deogarh district for this study. Rainfall data for17 years from 2001 to 2017 are collected for the presented study to make rainfall forecasting through different methods.

\section{Probability Distribution Functions}

For seasonal rainfall analysis of Deogarh district, three seasons- kharif (JuneSeptember), rabi (October to January) and summer (February to May) are considered.

The data is fed into the Excel spreadsheet, where it is arranged in a chronological order and the Weibull plotting position formula is then applied. The Weibull plotting position formula is given by

where $m=$ rank number

$$
p=\frac{m}{N+1}
$$

$$
N=\text { number of years }
$$

The recurrence interval is given by

$$
T=\frac{1}{p}=\frac{N+1}{m}
$$

The values are then subjected to various probability distribution functions namelynormal, log-normal (2-parameter), log-normal (3-parameter), gamma, generalized extreme value, Weibull, generalized Pareto distribution, Pearson, log-Pearson type-III and Gumbel distribution. Some of the probability distribution functions are described as follows:

\section{Normal Distribution}

The probability density is

$$
p(x)=(1 / \sigma \sqrt{2 \pi}) e^{-(x-\mu)^{2} / 2 \sigma^{2}}
$$

where $x$ is the variate, $\mu$ is the mean value of variate and $\sigma$ is the standard deviation. In this distribution, the mean, mode and median are the same. The cumulative probability of a value being equal to or less than $x$ is

$$
p(x \leq)=1 / \sigma \sqrt{2 \pi} \int_{-\infty}^{x} e^{-(x-\mu)^{2} / 2 \sigma^{2}} d x
$$

This represents the area under the curve between the variates of $-\infty$ and $x$.

\section{Log-normal (2-parameter) Distribution}

The probability density is

$$
p(x)=\left(1 / \sigma_{y} e^{y} \sqrt{2 \pi}\right) e^{-\left(y-\mu_{y}\right)^{2} / 2 \sigma_{y}}
$$

where $y=\ln x$, where $x$ is the variate, $\mu_{y}$ is the mean of $y$ and $\sigma_{y}$ is the standard deviation of $y$.

\section{Log-normal (3-parameter) distribution}

A random variable $X$ is said to have threeparameter log-normal probability distribution if its probability density function (pdf) is given by:

$$
=\left\{\begin{array}{c}
\frac{1}{(x-\lambda) \sigma \sqrt{2 \pi}} \exp \left\{-\frac{1}{2}\left(\frac{\log (x-\lambda)-\mu}{\sigma}\right)^{2}\right\}, \\
\lambda<x<\infty, \mu>0, \sigma>0 \\
0, \text { otherwise }
\end{array}\right\}
$$

where $\mu, \sigma$ and $\lambda$ are known as location, scale and threshold parameters, respectively.

Pearson Distribution:-

The general and basic equation to define the probability density of a Pearson distribution

$$
p(x)=e \int_{-\infty}^{x} \frac{a+x}{b_{0}+b_{1} x+b_{2} x^{2}} d x
$$

where $a, b_{0}, b_{1}$ and $b_{2}$ are constants.

The criteria for determining types of distribution are $\beta_{1}, \beta_{2}$ and $k$ where

$$
\begin{gathered}
\beta_{1}=\frac{\mu_{3}^{2}}{\mu_{2}^{3}} \\
\beta_{2}=\frac{\mu_{4}}{\mu_{2}^{2}} \\
k=\frac{\beta_{1}\left(\beta_{2}+3\right)^{2}}{4\left(4 \beta_{2}-3 \beta_{1}\right)\left(2 \beta_{2}-3 \beta_{1}-6\right)}
\end{gathered}
$$

Where $\mu_{2}, \mu_{3}$ and $\mu_{4}$ are second, third and fourth moments about the mean.

\section{Log-Pearson Type III Distribution}

In this the variate is first transformed into logarithmic form (base 10) and the transformed data is then analyzed. If $X$ is the variate of a random hydrologic series, then the series of $Z$ variates where

$$
z=\log x
$$

are first obtained. For this $\mathrm{z}$ series, for any recurrence interval $T$ and the coefficient of skew $C_{S}$,

$\sigma_{z}=$ Standard deviation of the $Z$ variate sample

$$
=\sqrt{\sum(z-\bar{z})^{2} /(N-1)}
$$

And $C_{s}=$ coefficient of skew of variate $Z$

$$
\begin{aligned}
&= \frac{N \sum(z-\bar{z})^{3}}{(N-1)(N-2) \sigma_{z}{ }^{3}} \\
& \bar{Z}=\text { mean of } z \text { values }
\end{aligned}
$$


$N=$ sample size $=$ number of years of record

\section{Generalized Pareto Distribution}

The family of generalized Pareto distributions (GPD) has three parameters $\mu, \sigma$ and $\xi$.

The cumulative distribution function is

$$
\begin{aligned}
& F_{(\varepsilon, \mu, \sigma)}(x) \\
& =\left\{\begin{array}{cc}
1-\left(1+\frac{\xi(x-\mu)}{\sigma}\right)^{\frac{-1}{\xi}} \text { for } \xi \neq 0 \\
1-\exp \left(-\frac{x-\mu}{\sigma}\right) & \text { for } \xi=0
\end{array}\right\}
\end{aligned}
$$

For $x \geq \mu$ when $\xi \geq 0$ and $x \leq \mu-\frac{\sigma}{\xi}$ when $\xi<0$, where $\mu \in \mathbb{R}$ is the location parameter, $\sigma>0$ the scale parameter and $\xi \in \mathbb{R}$ the shape parameter.

The probability density function is

$$
f_{(\xi, \mu, \sigma)}(x)=\frac{1}{\sigma}\left(1+\frac{\xi(x-\mu)}{\sigma}\right)\left(-\frac{1}{\xi}-1\right)
$$

Or

$$
f_{(\xi, \mu, \sigma)}(x)=\frac{\sigma^{\frac{1}{\xi}}}{(\sigma+\xi(x-\mu))^{\left(\frac{1}{\xi}+1\right)}}
$$

again, for $x \geq \mu$, and $x \leq \mu-\frac{\sigma}{\xi}$ when $\xi<0$

\section{Result and discussion}

The various parameters like mean, standard deviation, RMSE value were obtained and noted for different distributions. The rainfall at $90 \%, 75 \%, 50 \%, 25 \%$ and $10 \%$ probability levels are determined. The distribution "best" fitted to the data is noted down in a tabulated form in Table 1.

In the present study, the parameters of distribution for the different distributions have been estimated by FLOOD frequency analysis software. The rainfall data is the input to the software programme. The best fitted distribution of different month and seasons and annual were presented in Table 1.The annual rainfall in $50 \%$ probability was found to be $1514.8 \mathrm{~mm}$ for Deogarh block of Odisha. During Kharif at 50\% probability level, the rainfall is $1266.8 \mathrm{~mm}$ where as only $94.1 \mathrm{~mm}$ and $57.9 \mathrm{~mm}$ was received during rabi and summer respectively.

In the present study, the parameters of distribution for the different distributions have been estimated by FLOOD-flood frequency analysis software. The rainfall data is the input to the software programme. The best fitted distribution of different month and season and annual were presented in Table 6 . The annual rainfall in $50 \%$ probability was found to be $1514.8 \mathrm{~mm}$ for Deogarh district of Odisha. During Kharif at $50 \%$ probability level, the rainfall is $1266.8 \mathrm{~mm}$ where as only $94.1 \mathrm{~mm}$ and $57.9 \mathrm{~mm}$ was received during rabi and summer respectively.

In the present study, the parameters of distribution for the different distributions have been estimated by FLOOD-flood frequency analysis software. The rainfall data is the input to the software programme. The best fitted distribution of different month and season and annual were presented in Table 1 . The annual rainfall in $50 \%$ probability was found to be $1514.8 \mathrm{~mm}$ for Deogarh district of Odisha. During Kharif at $50 \%$ probability level, the rainfall is $1266.8 \mathrm{~mm}$ where as only $94.1 \mathrm{~mm}$ and $57.9 \mathrm{~mm}$ was received during rabi and summer respectively, so water harvesting structures may be made to grow crops during rabi and summer to utilize the water from the water harvesting structures to increase the cropping intensity of the area. It is also observed that at $75 \%$ probability level the July and Aug received more than $100 \mathrm{~mm}$, so farmers of these area can grow crops in upland areas suitably paddy can be grown followed by any rabi crop in rabi season like mustard or kulthi in upland areas. In Fig 1 the plot between different months and amount of rainfall in different probabilities were shown, It is observed that September month gets highest amount of rainfall compared to other months. Fig 2 shows the different cropping pattern in Deogarh district as per the rainfall available in different weeks. 
Table 1: Rainfall analysis of Deogarh Block at different probability levels for different months and seasons.

\begin{tabular}{|c|c|c|c|c|c|c|c|}
\hline \multirow{2}{*}{ Months } & \multirow{2}{*}{$\begin{array}{c}\text { Best-fit } \\
\text { Distribution }\end{array}$} & \multirow{2}{*}{$\begin{array}{l}\text { RMSE } \\
\text { Value }\end{array}$} & \multicolumn{5}{|c|}{ Rainfall at probability levels } \\
\hline & & & $90 \%$ & $75 \%$ & $50 \%$ & $25 \%$ & $10 \%$ \\
\hline January & EV type III & 0.07042 & - & - & - & 15.58 & 35.39 \\
\hline February & Log Pearson & 0.0601 & - & - & 2.39 & 11.01 & 33.33 \\
\hline March & Gamma & 0.05918 & - & - & 1.94 & 14.65 & 35.86 \\
\hline April & Gumbel maximum & 0.06675 & - & - & - & 15.63 & 32.71 \\
\hline May & Pareto & 0.0559 & - & 10.31 & 30.67 & 50.92 & 62.95 \\
\hline June & Pareto & 0.04176 & 47.66 & 75.44 & 131.26 & 210.24 & 289.36 \\
\hline July & Log Pearson & 0.05314 & 120.32 & 172.39 & 257.07 & 383.40 & 549.58 \\
\hline August & Log Pearson & 0.05038 & 150.24 & 208.19 & 283.06 & 365.09 & 440.71 \\
\hline September & Pareto & 0.05016 & 54.59 & 89.94 & 159.8 & 255.63 & 347.3 \\
\hline October & Pareto & 0.03902 & 0.8 & 13.14 & 39.26 & 79.94 & 126.85 \\
\hline November & EV type III & 0.07886 & - & - & - & 0.92 & 14.3 \\
\hline December & Pearson & 0.05428 & - & - & - & 3.42 & 20.18 \\
\hline Annual & GEV & 0.04222 & 1106.68 & 1305.33 & 1514.8 & 1704.11 & 1848.01 \\
\hline $\begin{array}{l}\text { Kharif } \\
\text { (June-Sep) }\end{array}$ & Log normal & 0.02898 & 956.11 & 1103.61 & 1266.8 & 1423.80 & 1552.52 \\
\hline $\begin{array}{l}\text { Rabi } \\
\text { (Oct-Jan) }\end{array}$ & Log Pearson & 0.05516 & 33.15 & 53.90 & 94.1 & 167.47 & 286.20 \\
\hline $\begin{array}{l}\text { Summer } \\
\text { (Feb-May) }\end{array}$ & Log Pearson & 0.04125 & 21.44 & 35.68 & 57.9 & 86.97 & 117.97 \\
\hline
\end{tabular}

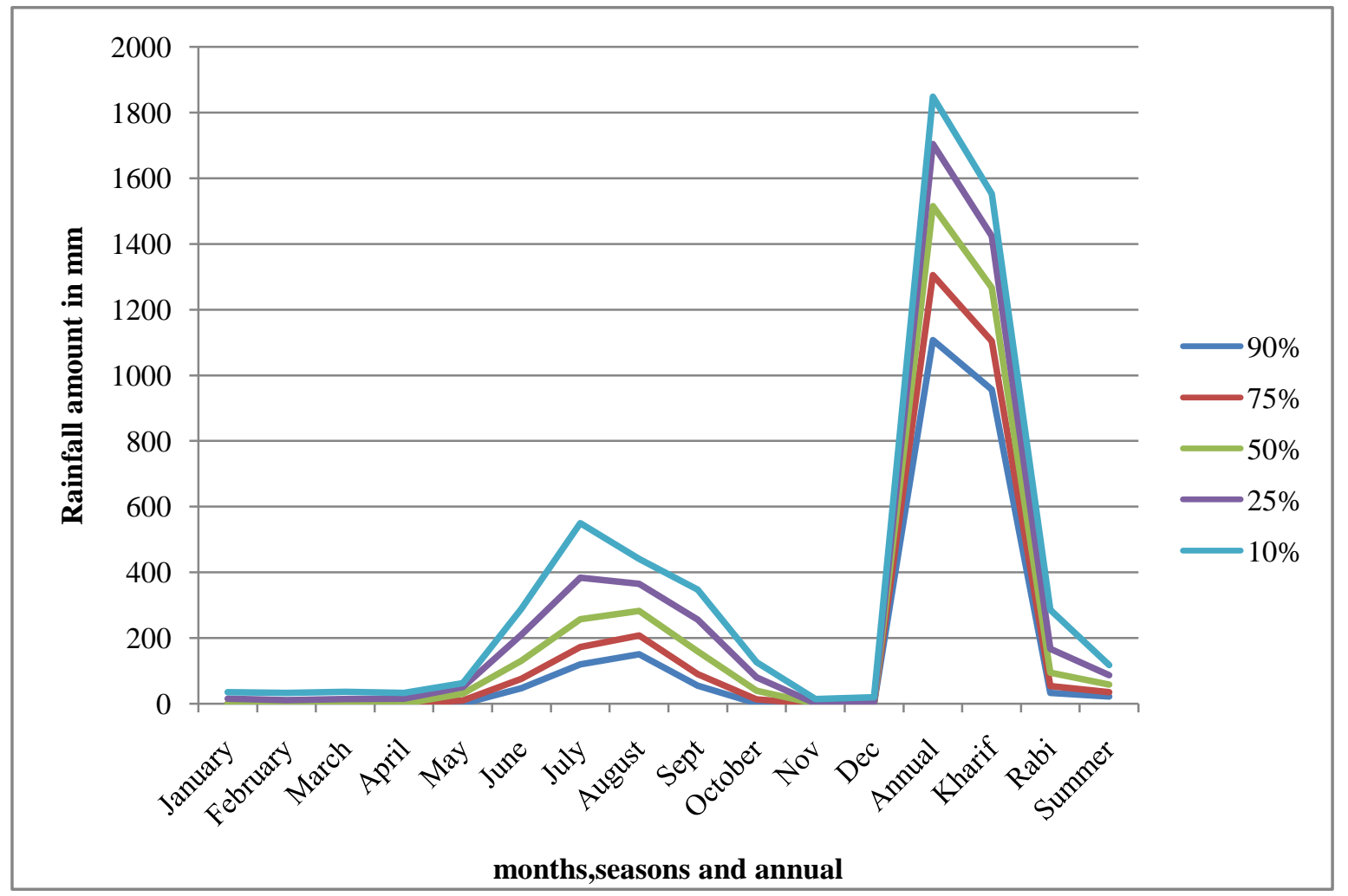

Fig 1: Rainfall at different probabilities of monthly, seasonal and annual at Deogarh block 


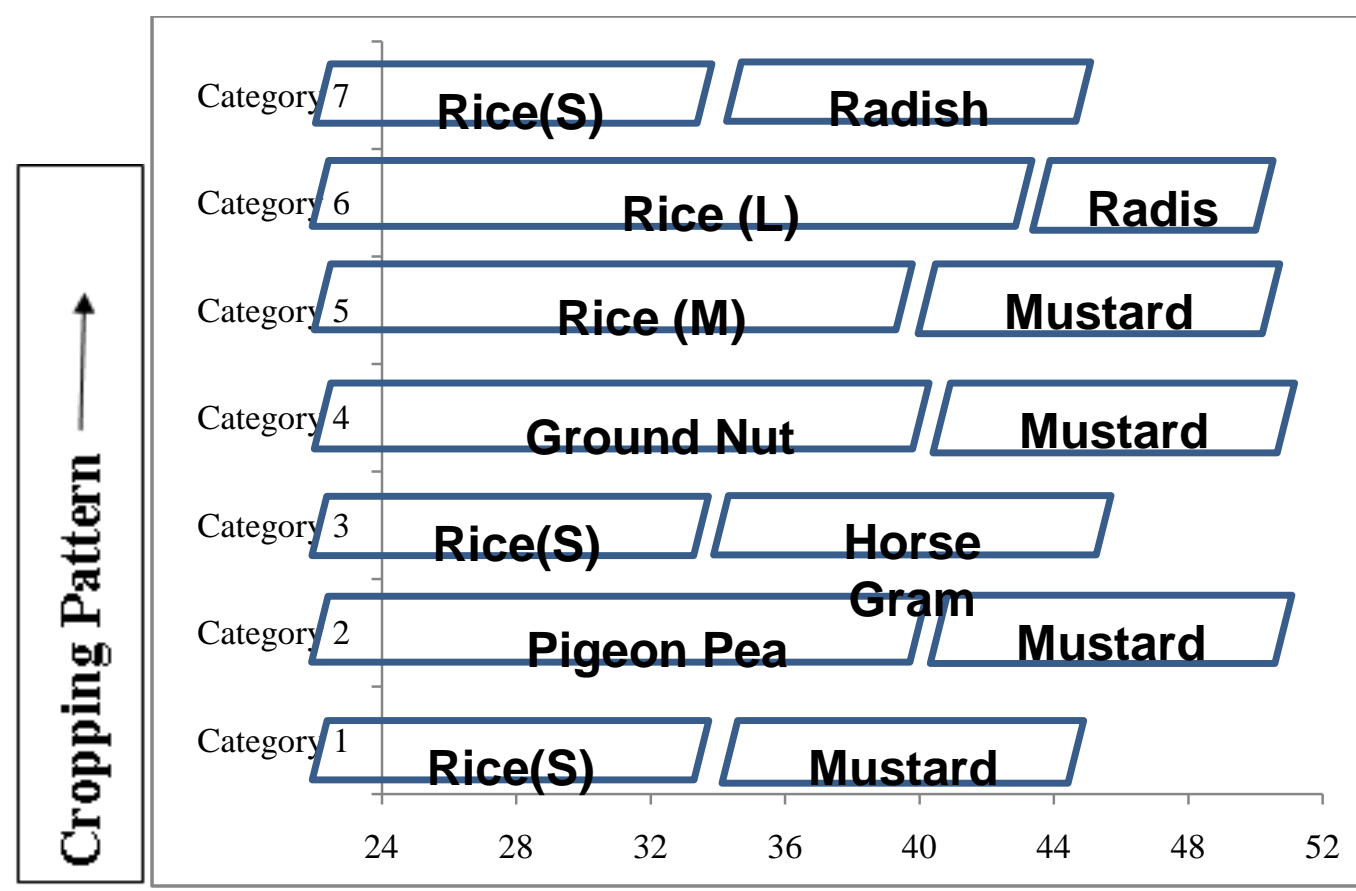

WEEKS (SMW) $\longrightarrow$

Fig. 2: Different cropping patterns for Deogarh district

\section{Conclusion}

Forecasting of rainfall is essential for proper planning of crop production. About $70 \%$ of cultivable land of Odisha depends on rainfall for crop production. Prediction of rainfall in advance helps to accomplish the agricultural operations in time. It can be concluded that, excess runoff should be harvested for irrigating post-monsoon crops. It becomes highly necessary to provide the farmers with high-yielding variety of crops and such varieties which require less water and are early-maturing in Deogarh district of Mahanadi command area of Odisha. It is also observed that at $75 \%$ probability level the July and Aug received more than $100 \mathrm{~mm}$, so farmers of these area can grow crops in upland areas suitably paddy can be grown followed by any rabi crop in rabi season like mustard or kulthi in upland areas. Annual rainfall of Deogarh district is $1514.8 \mathrm{~mm}$ at $50 \%$ probability level. It is observed that September month gets highest amount of rainfall compared to other months. Different cropping pattern selected may be may be practiced in this district.

\section{References}

Chow, V.T. (1964). Hand book of Applied Hydrology McGraw Hill Book Co., NewYork.8-28

Gumbel, E.J. 1954. Statistical theory of droughts. Proceedings of ASCE. 80(439) :1-19

Jat, M. L., Singh, R. V., Balyan, J. K., Jain, L.K., Sharma, R.K. 2006. Analysis of weekly rainfall for Sorghum based crop planning in Udaipur region. Indian Journal of Dry Land and Agricultural Research and Development, 21(2):114-122.

Kar, G., Singh, R., Verma, H.N. 2004. Alternative cropping strategies for assured and efficient crop production in upland rain fed rice areas of eastern India based on rainfall analysis. 67: 47-62.

Senapati, S. C., Sahu, A.P., Sharma, S.D. 2009. Analysis of meteorological events for crop planning in rain fed uplands. Indian Journal of Soil Conservation, 37(2):85-90 
Thom, H.C.S. (1966). Some methods of climatological analysis. WMO Tech. Note. No. 81.
Weibull, W. 1951. A statistical distribution functions of wide applicability. Journal of Applied MechanicalTransactions. ASME, 18(3):293-297. 